Usage, Usability, and Utility of 3D City Models, 03008 (2012)

DOI: $10.1051 / 3 \mathrm{u} 3 \mathrm{~d} / 201203008$

(c) Owned by the authors, published by EDP Sciences, 2012

\title{
Detailed modelling of the wind comfort in a city avenue at the pedestrian level
}

\author{
J.H. Amorim, J. Valente, C. Pimentel, A.I. Miranda and C. Borrego \\ CESAM \& Department of Environment and Planning, University of Aveiro, \\ 3810-193 Aveiro, Portugal
}

\begin{abstract}
The interrelations between microclimatic conditions and urban morphology determine the comfort of pedestrians in a city. This work evaluates the wind comfort, based on international criteria, in a $1.1 \mathrm{~km}$ long avenue. For this purpose the CFD model Fluent was applied. 3D virtual simulation domain was constructed from GIS file of the area using a CAD tool. Results show a very complex wind flow in this urban canyon, as a result of its architectural characteristics and relative wind direction. The orientation of the canyon relative to the prevailing wind direction, its configuration (namely its aspect ratio), the presence of tall buildings in the edge of the avenue, and the absence of trees, induce a swirling flow that increases in speed along its length, as a typical channelling effect. As a consequence, comfort conditions are very distinct in the different sections of the avenue. Based on this work, the areas that do not meet the comfort criterion were identified, supporting the implementation of adequate mitigation measures (as natural or artificial windbreakers).
\end{abstract}

\section{INTRODUCTION}

The interrelations between the microclimatic characteristics of a given area and the urban morphology determine the comfort of pedestrians. This aspect is particularly relevant in the definition of recreation areas for public use. In order to classify the usability of an urban space for outdoor activities several criteria for human comfort, relative to the intensity of the wind, were developed. Some of these guidelines take into account not only the wind velocity, but also the frequency of occurrence and the level of turbulence (e.g., [1]).

Within this framework, the objective of this work is to evaluate the wind comfort conditions, based on certified international criteria, in an avenue of the Portuguese city of Aveiro. This city is distinguished by its strong touristic identity, which is brought by its natural and made-made heritage, namely its lagoon and canals and the Art-Nouveau buildings. However, its location on the western coastline and its topographic features induce the frequent occurrence of strong winds that affect the comfort of those who enjoy the city's public spaces, in particular its main avenue: "Lourenço Peixinho" that connects the railway station with the centre. The goal is thus to evaluate how the climate of the region, associated with the geometrical characteristics of buildings, may affect the use of the outdoor space for leisure. This is particularly relevant due to the fact that a plan for the plantation of trees (that will substitute the old ones that were cut due to disease) is under discussion, stressing the need to identify the spots in the avenue where the requirements for human comfort are not guaranteed.

The work can be structured in three main components:

- Statistical analysis of a time series of measured meteorological data;

- Micro-scale simulation of the 3D behavior of the wind flow in the avenue applying a high detail numerical model;

This is an Open Access article distributed under the terms of the Creative Commons Attribution License 2.0, which permits unrestricted use, distribution, and reproduction in any medium, provided the original work is properly cited. 


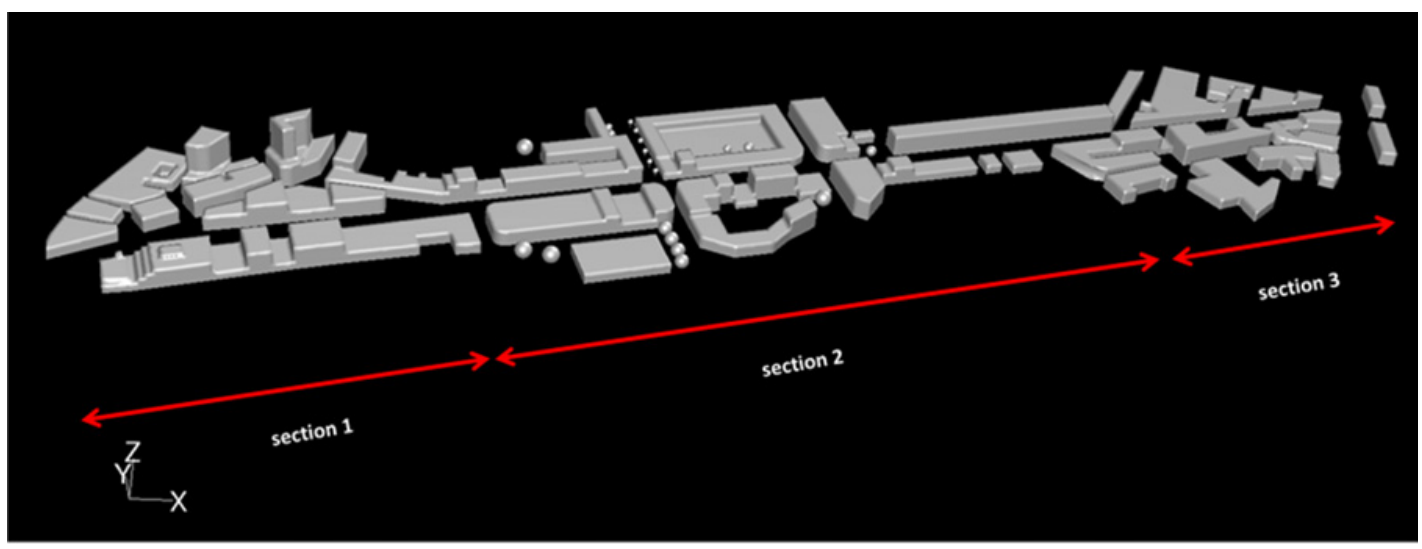

Figure 1. Virtual Avenue generated using CAD pre-processor Gambit.

- Assessment of the human comfort in the avenue based on the requirements established by a specific wind comfort criterion.

\section{CFD SIMULATION OF 3D WIND BEHAVIOR}

The numerical tool used was the Computational Fluid Dynamics (CFD) model Fluent ${ }^{\circ}$, which we have been applying in the simulation of urban air quality [2-5].

\subsection{Computational domain}

The study domain (see figure 1) was virtually defined using Fluent's CAD preprocessor Gambit. 3D coordinates were extracted from the city's GIS data.

The built-up area defined in the model covers 25 ha $(1100 \mathrm{~m} \times 230 \mathrm{~m})$. In order to create the conditions for the fully development of the atmospheric boundary layer the total area of the domain reaches the 131 ha, following the guidelines from COST 732 [6]. An unstructured meshing scheme (TGrid type) was used for discretizing the domain in more than 4 million computational cells. This method is indicated for meshing complex geometries.

\subsection{Input meteorological data}

Typical meteorological conditions were driven from the analysis of weather observations in Aveiro acquired in the period from 2005 to 2009. The statistical analysis of measured data is shown in the wind rose of figure 2. Because the objective of this work is to evaluate the outdoor use of the avenue only the winter months were considered, during the night period. It can be concluded that the North and Northwest winds represent approximately $50 \%$ of the time, under these circumstances.

From this analysis, 13 typical meteorological situations (see the table in figure 2) can be defined by the combination of distinct values of wind velocity and direction. Excluding the periods with no data available, these 13 cases represent $83 \%$ of the time, which gives a good representativeness of the atmospheric dynamics in this area.

\subsection{Modeling results}

Modeling results reveal a highly complex flow (see figure 3) that is induced by the aerodynamic effects of buildings and some isolated trees, as also by the incoming flow from the secondary streets, which 


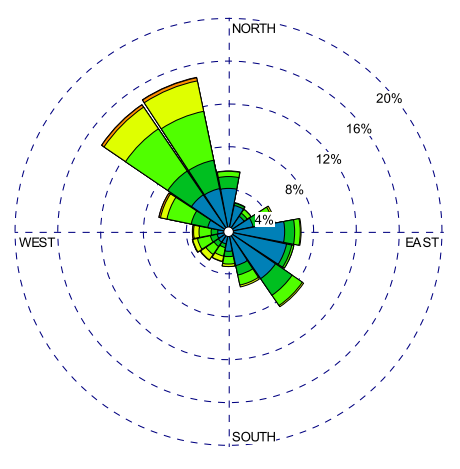

\begin{tabular}{|c|c|c|c|}
\hline & case & $\begin{array}{l}\text { wind velocity } \\
\left(\mathrm{m} \cdot \mathrm{s}^{-1}\right)\end{array}$ & $\begin{array}{l}\text { wind direction } \\
(\stackrel{\circ}{ })\end{array}$ \\
\hline & 1 & 1.30 & 292.5 \\
\hline & 2 & 2.85 & 292.5 \\
\hline & 3 & 4.65 & 292.5 \\
\hline & 4 & 7.25 & 292.5 \\
\hline & 5 & 1.30 & 315.0 \\
\hline & 6 & 2.85 & 315.0 \\
\hline & 7 & 4.65 & 315.0 \\
\hline & 8 & 7.25 & 315.0 \\
\hline 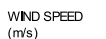 & 9 & 1.30 & 337.5 \\
\hline$\square>11.1$ & 10 & 2.85 & 337.5 \\
\hline$\square \quad \begin{array}{l}8.8-11.1 \\
5.7-8.8\end{array}$ & 11 & 4.65 & 337.5 \\
\hline$\square \begin{array}{r}3.6-5.7 \\
2.1-3.6\end{array}$ & 12 & 7.25 & 337.5 \\
\hline$\square \begin{array}{l}2.1-3.6 \\
0.5-2.1\end{array}$ & 13 & 9.95 & 337.5 \\
\hline
\end{tabular}

Figure 2. Wind rose for Aveiro city and case studies definition.

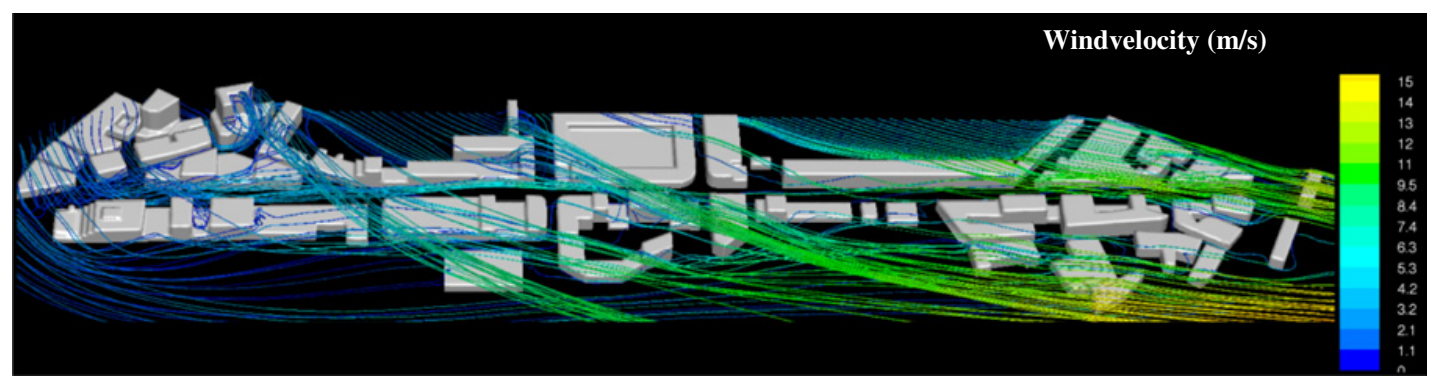

Figure 3. Visualization of wind flow path lines, as an example for case 11 (see the table in figure 2).

lead to the formation of vortices of variable magnitude and impact. A behavior that was common to all the cases simulated was the acceleration of wind along the avenue, with the higher speeds attained in section 3 .

It's in section 1 that the flow assumes the higher complexity, resulting from the formation of a spiraling flow that is induced by the blocking effect of the taller buildings and the strong updrafts that occur especially in this area (see figure 4).

The vertical component of the flow is represented in figure 5, as an example for case 7 (see the table in figure 2), showing an upward flux (red colored) close to the buildings on the North side of the avenue, which is compensated by a lighter downward flow (green colored) on the opposite side. This is the typical behavior of the wind flow in an urban canyon when the incoming wind is not aligned with the main axis of the road.

\section{ANALYSIS OF THE HUMAN COMFORT IN THE AVENUE}

For the classification of the adequacy of the avenue for pedestrian use the criterion developed by Willemsen and Wisse [7] has been applied, which results from a multidisciplinary effort of different experts, in particular architects and engineers, and constitutes the guideline currently applied in The Netherlands. This criterion identifies average wind velocities and corresponding frequencies of occurrence for three distinct activities: traversing, strolling and sitting (see table 1). A wind velocity of $5 \mathrm{~m} . \mathrm{s}^{-1}$ is considered as the threshold for the referred pedestrian activities. 


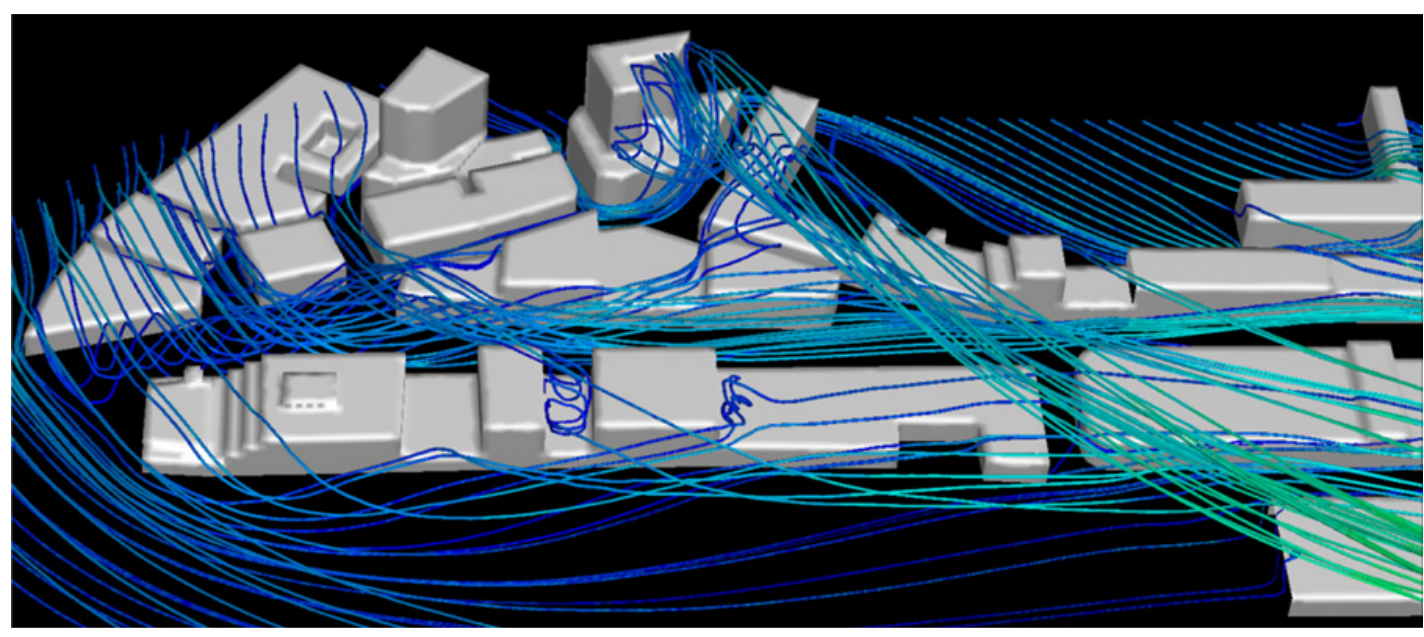

Figure 4. Zoom in over section 1 of the avenue.

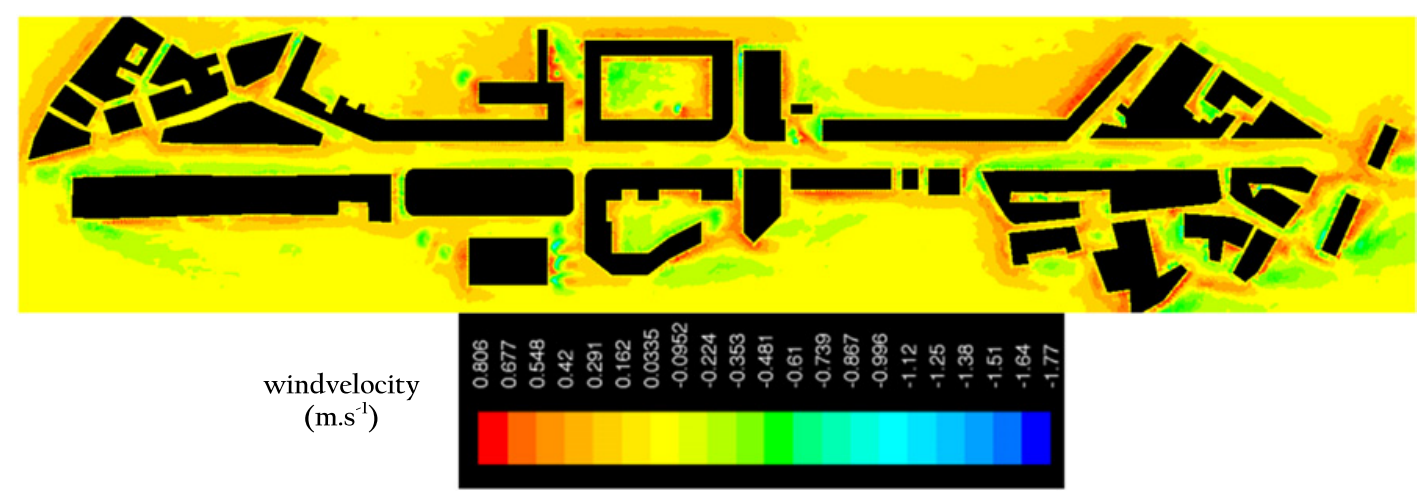

Figure 5. Top view of the vertical component of wind velocity at $1.5 \mathrm{~m}$ high, as an example for case 7 (see the table in figure 2). Buildings are shown in black.

Table 1. Wind comfort criteria for different pedestrian activities [7].

\begin{tabular}{|l|l|l|l|}
\hline Frequency of occurrence $\left(\right.$ vel. $\left.^{-} \mathbf{5 m} . \mathbf{s}^{\mathbf{- 1}}\right)(\mathbf{\%})$ & Traversing & Strolling & Sitting \\
\hline$<2.5$ & Good & good & good \\
\hline $2.5-5$ & Good & good & moderate \\
\hline $5-10$ & Good & moderate & poor \\
\hline $10-20$ & Moderate & poor & poor \\
\hline$>20$ & Poor & poor & poor \\
\hline
\end{tabular}

Based on the 3D spatial distribution of wind speed in the avenue for typical meteorological conditions (section 2) the human comfort can be evaluated by the crosswalk with the time frequency of each case study and the comparison with the information shown in table 1. Figure 6 presents the cases in which the threshold wind velocity of $5 \mathrm{~m} . \mathrm{s}^{-1}$ is exceed. It should be noted that only for cases 12 and 13 (see the table in figure 2) this threshold is exceeded in section 1, which has the highest potential in terms of touristic attractions. 


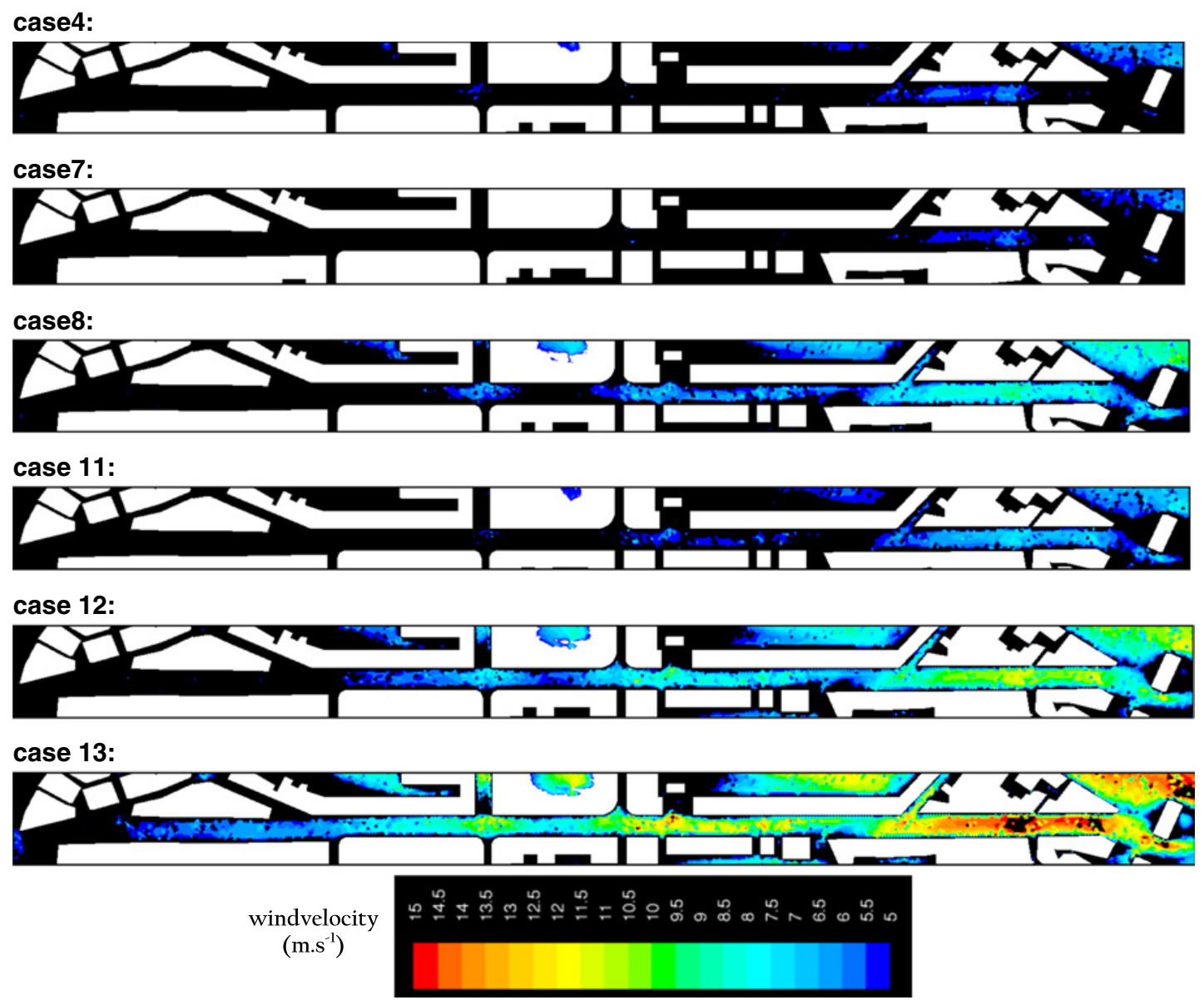

Figure 6. Identification of the study cases in which the wind speed surpasses the threshold of $5 \mathrm{~m} \cdot \mathrm{s}^{-1}$ (at $1.5 \mathrm{~m}$ high) established by the comfort criterion. Buildings are represented in white.

Table 2. Frequency of occurrence of wind speeds exceeding the threshold limit of $5 \mathrm{~m} \cdot \mathrm{s}^{-1}$ in the identified sections of the avenue.

\begin{tabular}{|l|l|l|l|}
\hline & section 1 & section 2 & section 3 \\
\hline Frequency of occurrence (vel. $\left.>\mathbf{5 m} . \mathbf{s}^{-\mathbf{1}}\right) \mathbf{( \% )}$ & 0.5 & 25.9 & 40.1 \\
\hline
\end{tabular}

Based on the outputs from the simulations and according to the comfort criterion adopted the time fractions in which the wind speed exceeds the threshold of $5 \mathrm{~m} \cdot \mathrm{s}^{-1}$ were calculated for the three sections of the avenue. The results from this analysis are presented in table 2.

The analysis of results reveals very distinct micrometeorological conditions in the three sections considered in the avenue. While section 1 fulfils the criteria in the majority of time, section 3 is classified as inadequate for traversing, strolling or sitting.

\section{FINAL CONCLUSIONS}

This modeling study aims to contribute to a better understanding of the impact of microscale atmospheric wind flow over the comfort of pedestrians in a $1.1 \mathrm{~km}$ long avenue. Results 
highlight the strong complexity of the flow in this urban canyon, as a result of its architectural characteristics.

The orientation of the canyon relative to the prevailing wind direction, its configuration (namely its aspect ratio), the presence of tall buildings in the edge of the avenue, and the absence of trees, induce a swirling flow that increases in speed along its length, following a typical channeling effect. As a consequence, comfort conditions are very distinct in the different sections of the avenue.

Some of the areas that do not meet the comfort criterion adopted in this study offer a set of features, especially in terms of available space, which may enhance the assessment and implementation of measures intended to mitigate the wind speed, namely, through the installation of natural or artificial windbreakers, as trees, shrubs, outdoors or fences in strategic locations. Such an evaluation should be performed on a subsequent CFD modeling study, aimed at the optimization of outdoor comfort conditions.

The authors would like to acknowledge the financial support of the Foundation for Science and Technology (FCT) through the Post-Doc grants of J.H. Amorim (SFRH/BPD/48121/2008) and J. Valente (SFRH/BPD/78933/2011), and the research project INSPIRAR (PTDC/AAC-AMB/103895/2008), supported in the scope of the Competitiveness Factors Thematic Operational Programme (COMPETE) of the Community Support Framework III and by the European Community Fund FEDER.

\section{References}

[1] J.H. Amorim, M. Lopes, C. Borrego, R. Tavares, A.I. Miranda, WIT Transactions on Ecology and the Environment 136 (18 ${ }^{\text {th }}$ Int. Conf. on Modelling, Monitoring and Management of Air Pollution, Greece, 2010)

[2] J.H. Amorim, V. Rodrigues, R. Tavares, C. Borrego, Advances in Urban Rehabilitation and Sustainability ( $3^{\text {rd }}$ WSEAS Int. Conf. on Urban Rehabilitation and Sustainability, Portugal, 2010)

[3] C. Borrego, O. Tchepel, A.M. Costa, J.H. Amorim, A.I. Miranda, AtmEnv, 37 (2003)

[4] A. Martins, M. Cerqueira, F. Ferreira, C. Borrego, J.H. Amorim, Int J Environ Pollut, 39 (2009)

[5] A.D. Penwarden, Building Science, 8 (1973)

[6] E. Willemsen, J.A. Wisse, J Wind EngIndAerod, 95 (2007)

[7] J. Franke, A. Hellsten, H. Schlünzen, B. Carissimo, COST Action 732, Quality Assurance and Improvement of Microscale Meteorological Models (2007) 